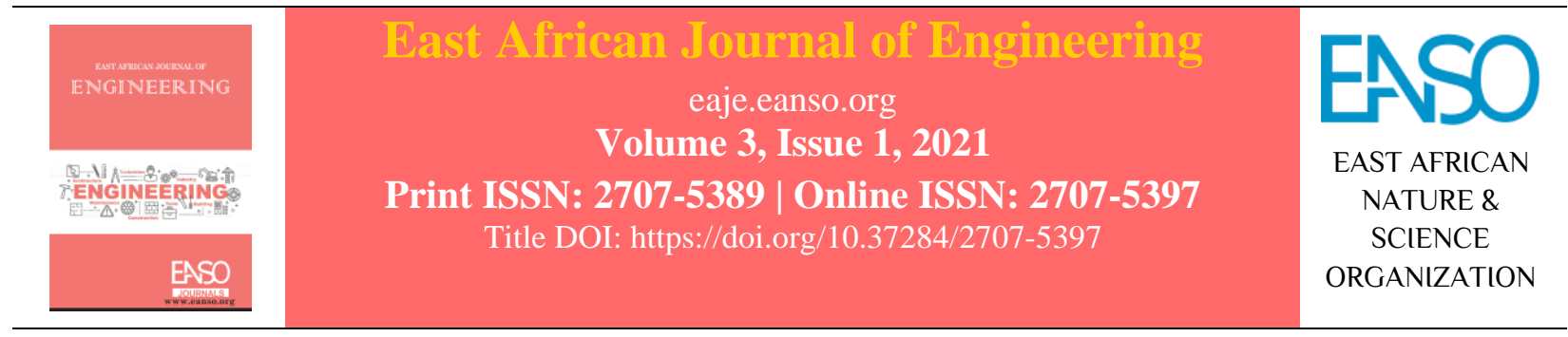

Original Article

\title{
Modelling the Influence of Evaporation on Residual Chlorine in Water Storage Tanks Using CFD.
}

\author{
John Tulirinya ${ }^{1 *}$, Richard O. Awichi ${ }^{1}$, Fulgensia Kamugisha Mbabazi ${ }^{1}$ \& Moses Nagulama ${ }^{1}$ \\ ${ }^{1}$ Department of Mathematics, Busitema University, P. O. Box 236 Tororo, Uganda. \\ * Author for Correspondence ORCID: https://orcid.org/0000-0001-7694-3652; Email: tulirinyajohn@gmail.com
}

Article DOI: https://doi.org/10.37284/eaje.3.1.357

\begin{abstract}
Publication Date: ABSTRACT
08 July 2021 Water storage tanks are usually utilized in water distribution systems (WDS) to meet the water demand fluctuations. Chlorine is the most common

Keywords: disinfectant used to disinfect water supplies. However, variations in the rate of chlorine decay in these storage tanks are one of the greatest limiting factors

Chlorine Decay, Water Treatment,

$C F D$,

OpenFoam,

Evaporation. in ensuring adequate water treatment process and giving guarantee to its efficiency. These variations could be due to some inadequately tested mechanisms of chlorine reactions in bulk fluid, chlorine reactions with storage tank walls, and natural evaporation. This study presents Computational Fluid Dynamics (CFD) modelling approach to assess the influence of evaporation on residual chlorine in water storage tanks. Findings indicate that an increase in the evaporation rate accelerates the rate at which residual chlorine is lost. It is concluded that temperature is the main factor influencing evaporation, which in turn causes the disappearance of residual chlorine within the water storage tanks.
\end{abstract}

\section{APA CITATION}

Tulirinya, J., Awichi, R. O., Mbabazi, F. K., \& Nagulama, M. (2021). Modelling the Influence of Evaporation on Residual Chlorine in Water Storage Tanks Using CFD. East African Journal of Engineering, 3(1), 33-49. https://doi.org/10.37284/eaje.3.1.357

\section{CHICAGO CITATION}

Tulirinya, John, Richard O. Awichi, Fulgensia. Kamugisha Mbabazi, \& Moses Nagulama. 2021. "Modelling the Influence of Evaporation on Residual Chlorine in Water Storage Tanks Using CFD". East African Journal of Engineering 3 (1), 33-49. https://doi.org/10.37284/eaje.3.1.357.

\section{HARVARD CITATION}

Tulirinya, J., Awichi, R. O., Mbabazi, F. K., and Nagulama, M. (2021) "Modelling the Influence of Evaporation on Residual Chlorine in Water Storage Tanks Using CFD”, East African Journal of Engineering, 3(1), pp. 33-49. doi: 10.37284/eaje.3.1.357.

\section{IEEE CITATION}

J., Tulirinya., R. O. Awichi., F. K. Mbabazi., \& Nagulama, M. "Modelling the Influence of Evaporation on Residual Chlorine in Water Storage Tanks Using CFD,” EAJE, vol. 3, no. 1, pp. 33-49, Jul. 2021.

33 | This work is licensed under a Creative Commons Attribution 4.0 International License. 
East African Journal of Engineering, Volume 3, Issue 1, 2021

Article DOI: https://doi.org/10.37284/eaje.3.1.357

\section{MLA CITATION}

Tulirinya, John, Richard O. Awichi, Fulgensia Kamugisha Mbabazi, \& Moses Nagulama. "Modelling the Influence of Evaporation on Residual Chlorine in Water Storage Tanks Using CFD.” East African Journal of Engineering, Vol. 3, no. 1, Jul. 2021, pp. 33-49, doi:10.37284/eaje.3.1.357.

\section{INTRODUCTION}

The study of chlorine decay phenomena is of prime importance in water treatment processes, mainly due to the different mechanisms involved in the chlorine decay process. These mechanisms include bulk decay, wall decay and evaporation (Noh et al., 2016). Bulk decay involves the reaction of chlorine with the water; wall decay involves the reaction of chlorine with the wall of the tank, while evaporation involves the conversion of the liquid phase to the vapour phase. Application, monitoring and control of the chlorination process are necessary to meet both chlorine demand and residual chlorine in water distribution systems. Residual chlorine ensures that there is no water re-contamination with different micro-organisms, and therefore water consumers are supplied with safe water for various consumptions.

After water treatment processes such as coagulation, flocculation, sedimentation and sand filtration, water is subjected to disinfection in order to kill any remaining micro-organisms; and to protect the water from germs when it is piped to various destinations (Pickford, 1996). The most commonly used method for water disinfection in developing countries is chlorine dosing since a residual concentration of chlorine is essential throughout the water distribution systems to prevent re-contamination of micro-organisms.

Typical forms of chlorine used in water treatment are; Elemental chlorine which is in either liquid or gaseous form, Hypochlorite and Chlorine Dioxide (Clasen \& Edmondson, 2006). Chlorine reacts with water to form hypochlorous and hydrochloric acids, i.e.:

$$
\mathrm{Cl}_{2}+\mathrm{H}_{2} \mathrm{O} \rightarrow \mathrm{HOCl}+\mathrm{H}^{+} \mathrm{Cl}^{-}
$$

Here, $\mathrm{Cl}_{2}$ is the chlorine, $\mathrm{H}_{2} \mathrm{O}$ is water, $\mathrm{HOCl}$ is hypochlorous acid and $\mathrm{H}^{+} \mathrm{Cl}^{-}$is hydrochloric acid. The hypochlorous acid further reacts with water as follows;

$$
\mathrm{HOCl}+\mathrm{H}_{2} \mathrm{O} \rightarrow \mathrm{H}_{3} \mathrm{O}^{+}+\mathrm{OCl}^{-}
$$

It is the hypochlorous acid $(\mathrm{HOCl})$ and hypochlorite ions $\left(\mathrm{OCl}^{-}\right)$which have the disinfection potential and are referred to as free chlorine.

On many occasions, as shown in Figure 1, chlorine is noted to disappear within the storage tanks. Thus, monitoring residual chlorine in storage tanks is so important and this provokes the need to assess the influence of evaporation on residual chlorine in water storage tanks. 
Figure 1: Physico-chemical mechanisms involved in chlorine disappearances in a water storage tank

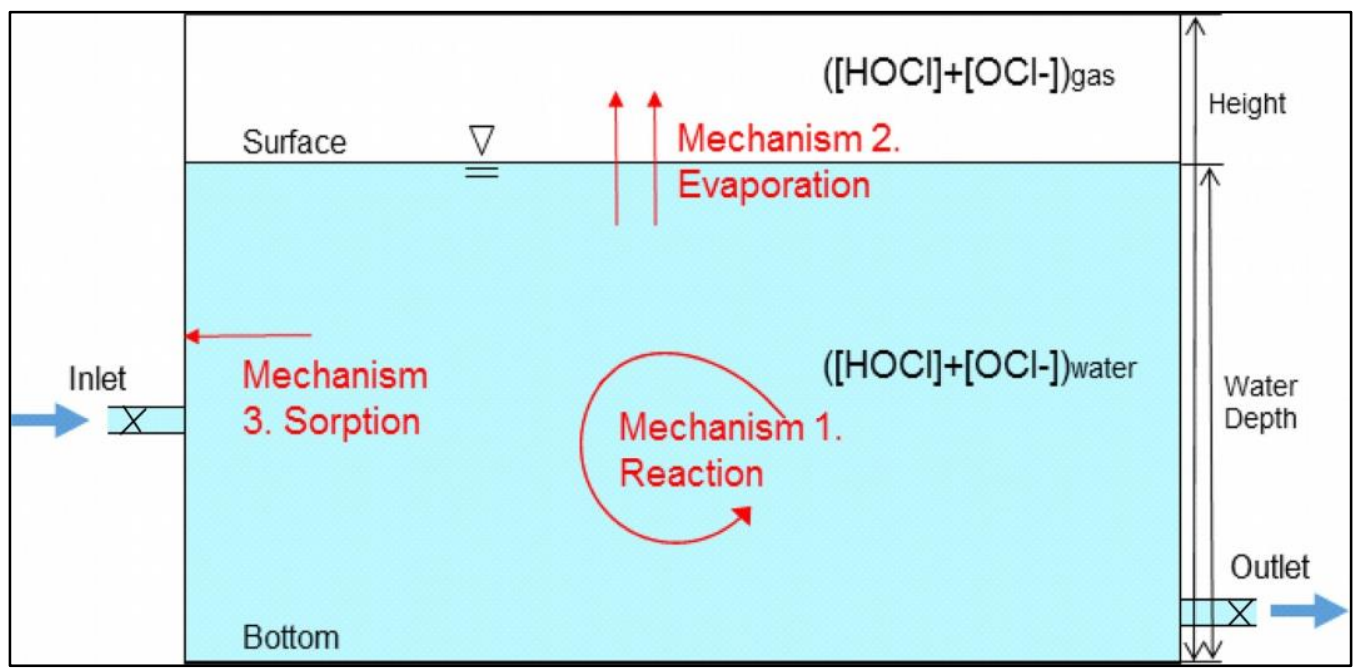

Source: (Noh et al., 2016).

\section{MATERIALS AND METHODS}

Phase Transport Equations

According to Vyzikas et al. (2015), the phase transport equation for both the liquid and vapour phases in OpenFOAM are written as follows respectively;

$$
\begin{aligned}
& \frac{\partial \rho_{l} \alpha_{l}}{\partial t}+\nabla \cdot\left(\rho_{l} \alpha_{l} V_{l}\right)=\dot{m}_{l} \\
& \frac{\partial \rho_{v} \alpha_{v}}{\partial t}+\nabla \cdot\left(\rho_{v} \alpha_{v} V_{v}\right)=\dot{m}_{v}
\end{aligned}
$$

These can be expressed as;

$\frac{\partial_{\propto_{l}}}{\partial_{t}}+\nabla \cdot\left(\propto_{l} V_{l}\right)=\frac{\dot{m}_{l}}{p_{l}}$

$\frac{\partial_{\propto_{v}}}{\partial_{t}}+\nabla \cdot\left(\propto_{v} V_{v}\right)=\frac{\dot{m}_{v}}{p_{v}}=\frac{-m_{l}}{p_{v}}$

since $m^{\cdot}{ }_{v}=-m^{\cdot}{ }_{l}$ by Sun et al. (2014).

Equations 5 and 6 can be combined to have one equation as;

$$
\frac{\partial \alpha_{n}}{\partial t}+\nabla \cdot\left(\alpha_{n} V_{n}\right)= \pm \frac{\dot{m}_{l}}{\rho_{n}}
$$

where $m^{\cdot}{ }_{l}=m^{\cdot}{ }_{c}-m_{e}$ and $n$ is the phase type.

It should be noted that $\alpha_{l}+\alpha_{v}=1$

The phase transport equation for liquid phase is implemented in OpenFOAM as;

$$
\frac{\partial \alpha_{l}}{\partial t}+\nabla \cdot\left(\alpha_{l} V\right)+\nabla \cdot\left(\alpha_{l} \alpha_{v} V_{\Omega}\right)=\frac{\dot{m}_{c}+\dot{m}_{e}}{\rho_{l}}
$$

where $V_{\Omega}=V_{l}-V_{v}$, the term $V_{\Omega}$ is introduced to ensure that the liquid-vapour interface is compressed to prevent a jump in the fluid variables as molecules change from liquid to vapour. $\alpha_{l}$ is the liquid phase fraction, $\alpha_{v}$ is the vapour phase fraction, the term $\alpha_{l} \alpha_{v}$ ensures that the term $V_{\Omega}$ is only active at the liquid-vapour interface, $\rho_{l}$ is the liquid density, $V$ is the fluid velocity vector, and $t$ is time.

The change in the transport properties of individual phases is averaged to get the properties of a homogeneous phase. These are implemented in OpenFOAM software (Jasak 1996) as follows; 
$p=\propto_{l} p_{l}+\propto_{l} p_{l}$

$\mu=\propto_{l} \mu_{l}+\propto_{v} \mu_{v}$

$k=\frac{k_{l} k_{v}}{\propto_{l} k_{l}+\propto_{v} k_{v}}$

$c_{p}=\propto_{l} c_{p l}+\propto_{v} c_{p v}$

where $\mu_{l}$ and $\mu_{v}$ are the liquid and vapour viscosities respectively, $k_{l}$ and $k_{v}$ are the liquid and vapour thermal conductivities respectively, $c_{p l}$ and $c_{p v}$ are the liquid and vapour specific heat capacities, respectively.

\section{Evaporation Model}

In the interest of evaporation only, we considered the Hertz-Knusden formula, which is grounded on kinetic theory for gases (Persad \& Ward, 2016). The equation is as follows;

$$
\dot{m}_{e}=C_{e} \sqrt{\frac{M}{2 \pi R T_{\text {sat }}}} \cdot\left(P^{*}-P_{\text {sat }}\right)
$$

where $m_{e}$ is the evaporation rate, $P^{*}$ is the vapour partial pressure, $P_{v}$ is vapour pressure, $M$ is the molar mass, $C_{e}$ is the evaporation accommodation coefficient, $P_{\text {sat }}$ and $T_{\text {sat }}$ are saturated pressure and temperature respectively, and $R$ is the universal gas constant.

Relating pressure to temperature for saturation condition, the Clausius-Clapeyron equation is used (Koutsoyiannis, 2012). This is written as;

$$
\frac{d P}{d T}=\frac{H}{T_{s a t}\left(\phi_{v}-\phi_{l}\right)}
$$

where $\varphi_{v}$ and $\varphi_{l}$ are inverse of the vapour density and liquid density, respectively, $H$ is the latent heat of vaporization $(\mathrm{J} / \mathrm{kg})$. By separating variables, Equation 14 is written as;

$$
d P=\frac{H}{T_{s a t}\left(\phi_{v}-\phi_{l}\right)} d T
$$

Assuming that $T^{*}$ and $P^{*}$ are close to the saturation condition, $P_{\text {sat }}$ and $T_{\text {sat }}$, Equation 15 yields;

$$
\left(P^{*}-P_{\text {sat }}\right)=\frac{H}{T_{\text {sat }}\left(\phi_{v}-\phi_{l}\right)}\left(T^{*}-T_{\text {sat }}\right)
$$

Substituting Equation 16 into Equation 13 yields;

$\dot{m}_{e}=C_{e} \sqrt{\frac{M}{2 \pi R T_{\text {sat }}}} \cdot\left(\frac{H}{T_{\text {sat }}\left(\phi_{v}-\phi_{l}\right)}\left(T^{*}-T_{\text {sat }}\right)\right)$

Equation 17 can be written as;

$\dot{m}_{e}=C_{e} \sqrt{\frac{M}{2 \pi R T_{s a t}}} \cdot H \cdot\left(\frac{\rho_{l} \rho_{v}}{\rho_{l}-\rho_{v}}\right)\left(\frac{T^{*}-T_{s a t}}{T_{s a t}}\right)$

Equation 18 was implemented in OpenFOAM to solve for evaporation.

\section{Mathematical Model Equations}

\section{Conservation of Mass}

Assuming that the diffusive fluxes for transport of density are neglected, the equation for conservation of mass, which is also referred to as equation of continuity is written in its differential form as;

$$
\frac{\partial \rho}{\partial t}+\nabla \cdot(\rho V)=0
$$

where $\rho$ is density, $t$ is time, and $\mathrm{V}$ is flow velocity vector field. 
For incompressible flows, equation (19) becomes;

$\nabla \cdot \mathrm{V}=0$

\section{Conservation of Momentum}

According to Batchelor (1967), the equation of motion is written in its conservative form as;

$\frac{\partial(\rho V)}{\partial t}+\nabla \cdot(\rho V V)=-\nabla p+\nabla \cdot \tau+\rho g+F$

where $\tau$ is the deformation tensor and $F$ is the continuum surface force (CSF) vector expressed by Brackbill et al. (1992) as follows;

$T=\pi\left(\nabla V+\nabla V^{T}\right)$

$\frac{\partial \rho V}{\partial t}+\nabla \cdot(\rho V V)=-\nabla p_{-r g h}-g \cdot h \nabla \rho+\nabla \cdot\left[\mu\left(\nabla V+\nabla V^{T}\right)\right]+\sigma \kappa \nabla \alpha$

where the surface curvature $\kappa$ is defined by Sun et al. (2014) as;

$$
\kappa=-\nabla \cdot \frac{\nabla \alpha}{|\nabla \alpha|}
$$

where $\mu$ is dynamic viscosity, $\rho$ is the fluid density, $V$ is fluid velocity vector, $p-r g h$ is pressure excluding hydrodynamic pressure, $g$ is the acceleration due to gravity, $\sigma$ is the surface tension, and $\alpha$ is phase fraction.

\section{Conservation of Energy}

Leaving out the specific kinetic energy term as the fluid motion considered here is low, the energy equation suggested by Sun et al. (2014) is given by;
$F=\sigma k\left(\frac{2 p}{p_{l}+p_{v}}\right) \nabla \propto \approx \sigma k \nabla \propto$

The modified pressure ' $p-\rho g h$ ' in OpenFOAM code is adopted in inter Condensating Evapourating Foam Solver removing the hydrostatic pressure $\rho g h$ from the pressure $p$. This is very vital in order to specify pressure at the boundaries of a space domain. The gradient of pressure,

$\nabla p$ is written as;

$$
\nabla p=\nabla p-r g h+\nabla(\rho g \cdot h)
$$

But $\nabla(\rho g \cdot h)=\rho g+g \cdot h \nabla \rho$, hence Equation 2) becomes;

$$
\nabla p=\nabla p-r g h+\rho g+g \cdot h \nabla \rho
$$

Substituting Equations 22, 23 and 25 into Equation 21 yields;

$$
\begin{aligned}
& {\left[\mu\left(\nabla V+\nabla V^{T}\right)\right]+\sigma \kappa \nabla \alpha} \\
& \quad \frac{\partial \rho h}{\partial t}+\nabla \cdot(\rho h V)=\nabla \cdot(k \nabla T)+S_{o}
\end{aligned}
$$

where $S_{o}$ is the source term defined as $S_{o}=m^{*} * h, h$ is the specific energy. where;

$$
h=\frac{\alpha_{l} \rho_{l} h_{l}+\alpha_{v} \rho_{v} h_{v}}{\alpha_{l} \rho_{l}+\alpha_{v} \rho_{v}}
$$

With

$$
h_{l}=c_{p l}(T-299.15), h_{v}=c_{p v}(T-299.15)
$$

\section{Kinetics of Chlorine Decay in Water Reservoirs}

According to Rossman et al. (1994), the decay rate of residual chlorine due to different reactions within the bulk aqueous phase is assumed to be in proportion to its concentration. This is expressed as;

37 | This work is licensed under a Creative Commons Attribution 4.0 International License. 
East African Journal of Engineering, Volume 3, Issue 1, 2021

Article DOI: https://doi.org/10.37284/eaje.3.1.357

$$
\frac{d C_{r}}{d t}=-\eta C_{r}
$$

where $C_{r}$ is the residual chlorine at the time $t$ and $\eta$ is the decay rate constant. Solving Equation 31 yields;

$$
\mathrm{Cr}=\mathrm{Coe}-\eta \mathrm{t}
$$

where $C_{o}$ is the initial chlorine concentration. Different scholars like Rossman et al. (1994), Chambers (1995), AWWARF (1996), among others, define the first-order decay rate coefficient $\eta$ as;

$$
\eta=\eta_{b}+\eta_{w}
$$

where $\eta_{b}$ and $\eta_{w}$ are the chlorine bulk decay and wall decay rate constants, respectively. In order to add the evaporation rate constant, $\left(m_{e}{ }^{*}\right)$ to the first-order chlorine decay model in equation (32), we added it by expressing the first-order decay rate coefficient $\eta$ as;

$\eta=\eta_{b}+\eta_{w}+\dot{m}_{e}$

Hence Equation 32 becomes:
$C_{r}=C_{o e}-\left(\eta^{b}+\eta^{w}+\dot{m}^{e}\right) t$

Equation 33 can then be used to calculate the residual chlorine in the water at any time, $t$.

Although various researchers like Powell et al. (2000), Hua et al. (1999) and many others have put a lot of efforts into studying the factors affecting both chlorine bulk $\left(\eta_{b}\right)$ and wall decay $\left(\eta_{w}\right)$ constants, the rate of evaporation $\left(m_{e}{ }^{*}\right)$ and factors influencing it have been completely left out.

\section{Experimental Determination of Residual Chlorine}

The materials that were used in determining residual chlorine in water include a Digital colorimeter, test tube, water under test, DPD powder and a beaker. DPD powder was added to the water sample in a test tube after being collected using a beaker from the water storage tank. Water in the test tube changed the colour to pink, and the test tube was later inserted into the meter that read the residual chlorine automatically. The results at different temperatures were as in Table 1.

The graph of residual chlorine against temperature is depicted in Figure 2. It shows a steady drop in RCI with increase in temperature.

Table 1: Table showing residual chlorine in water at different Temperatures in a water storage tank.

\begin{tabular}{ll}
\hline Temperature $(\mathbf{K})$ & Residual Chlorine(mg/l) \\
\hline 300.15 & 0.80 \\
299.95 & 0.87 \\
299.85 & 0.93 \\
299.55 & 0.94 \\
299.45 & 1.00 \\
299.15 & 1.05 \\
299.15 & 1.13 \\
299.05 & 1.20 \\
298.85 & 1.24 \\
298.75 & 1.30 \\
\hline
\end{tabular}

38 This work is licensed under a Creative Commons Attribution 4.0 International License. 
Figure 2: A graph of residual chlorine concentration against temperature in a water storage tank.

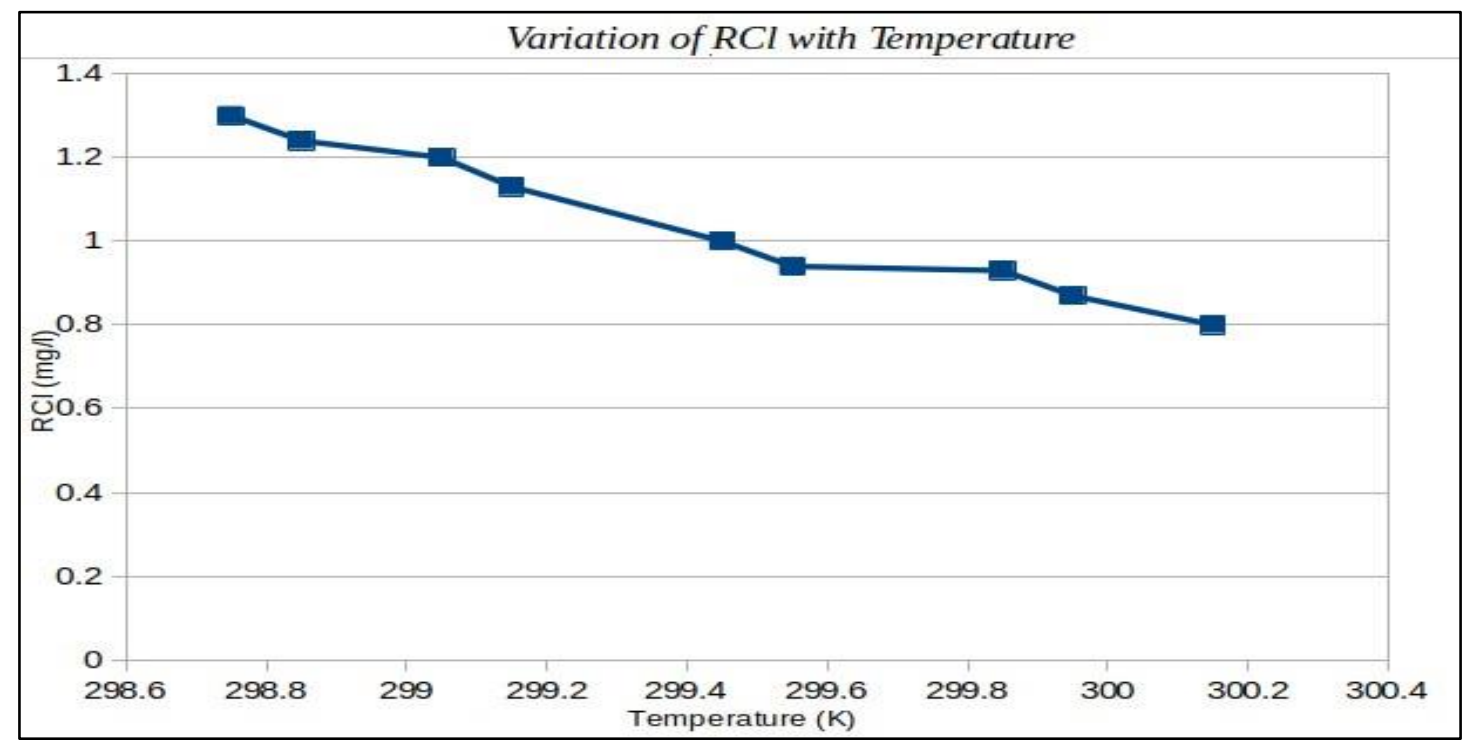

\section{Numerical Simulation and Results}

\section{Temperature, Velocity and Pressure Distributions}

At the beginning of the experiment, the temperature distribution is stratified due to the fixed temperature boundary condition specified at the top wall of the storage tank. A no-slip boundary condition is applied to all the walls of the water storage tank. The top wall is fixed at a uniform temperature of 318.15
$\mathrm{K}$. The other walls are maintained at zero-gradient temperature condition. The vapour velocity is initially $\left(\begin{array}{lll}0 & 0 & 0\end{array}\right) \mathrm{m} / \mathrm{s}$

Figure 3 shows the water temperature contours within a water storage tank. We observe that the temperature increases with time. The temperature increase is primarily near the top wall because of the temperature boundary condition. A plot of temperature against time shown in

Figure 3: Temperature distribution at $t=0,15,30$ and 45 seconds for water in a storage tank

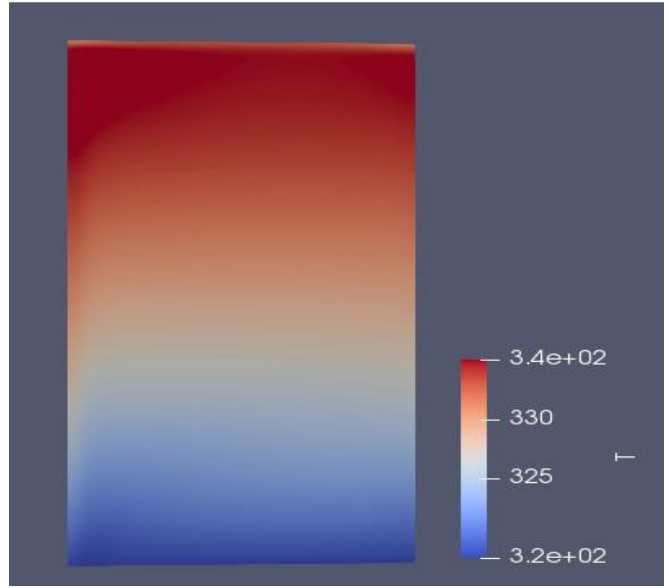

(a) $\mathrm{t}=0$ seconds

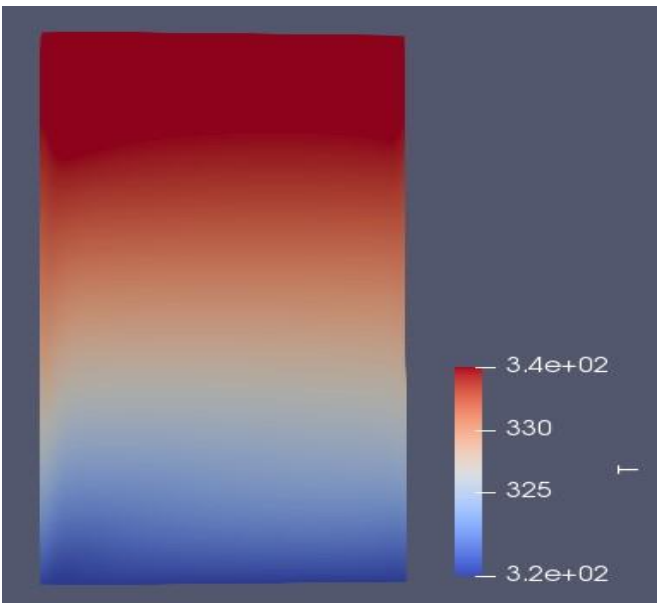

(b) $\mathrm{t}=15$ seconds

39 | This work is licensed under a Creative Commons Attribution 4.0 International License. 


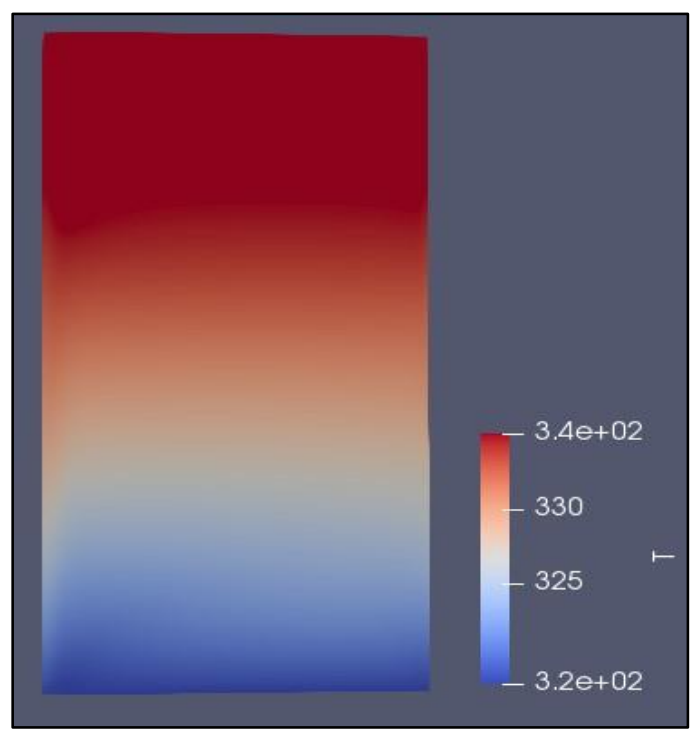

(c) $\mathrm{t}=30$ seconds

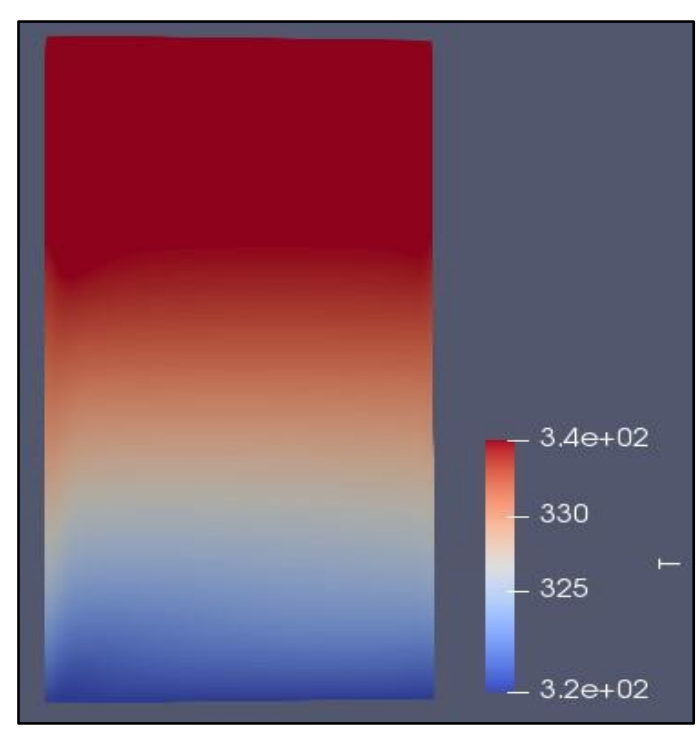

(d) $\mathrm{t}=45$ seconds

Figure 4 confirms the rise in temperature over time.

Figure 4: A graph of temperature against time within a water storage tank

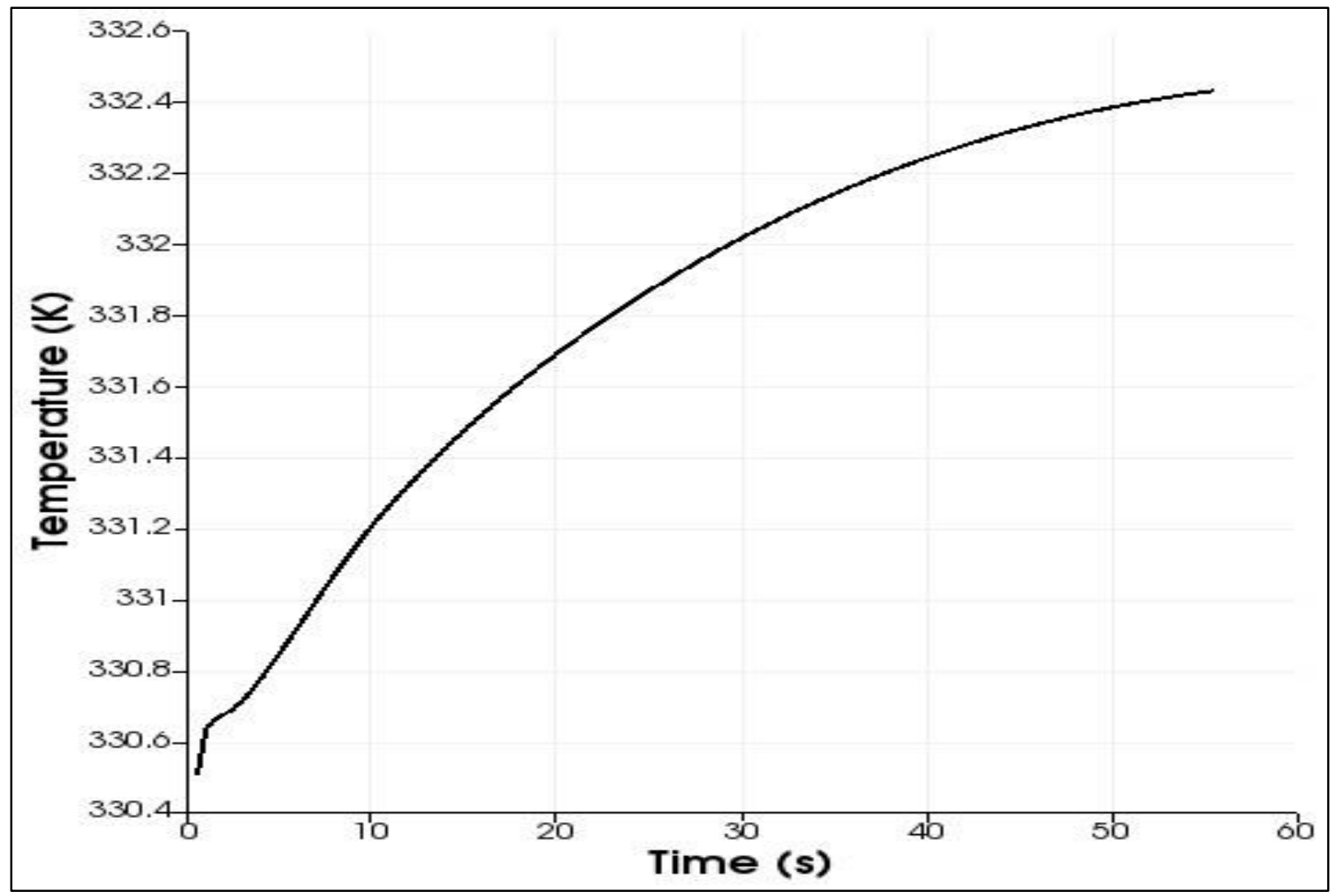

40 This work is licensed under a Creative Commons Attribution 4.0 International License. 
Figure 5: Vapour velocity distribution at $\mathrm{t}=0,15,30$ and 45 seconds, within a water storage tank.

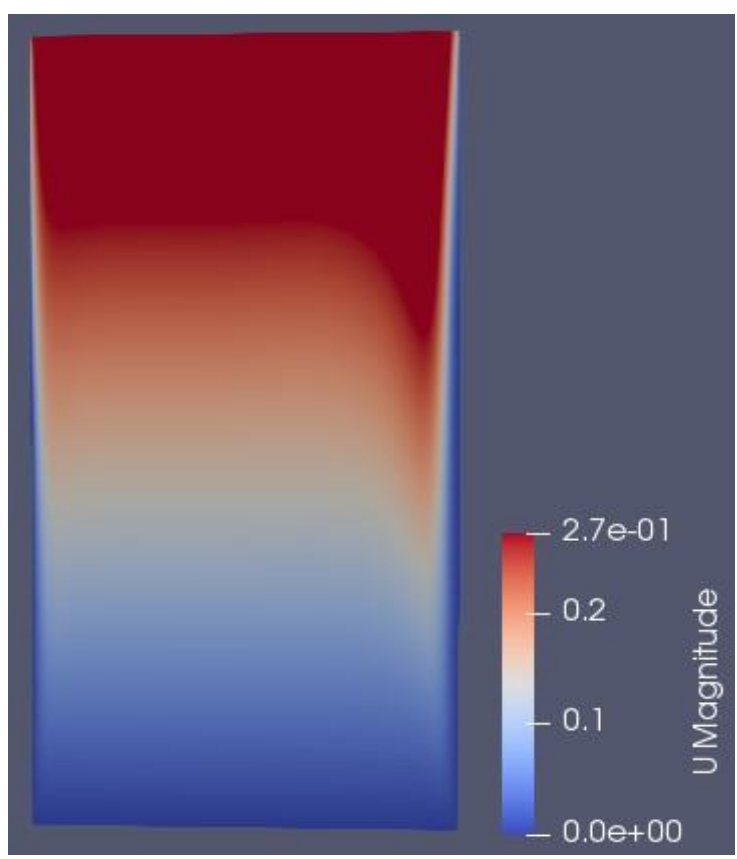

(a) $\mathrm{t}=0$ seconds

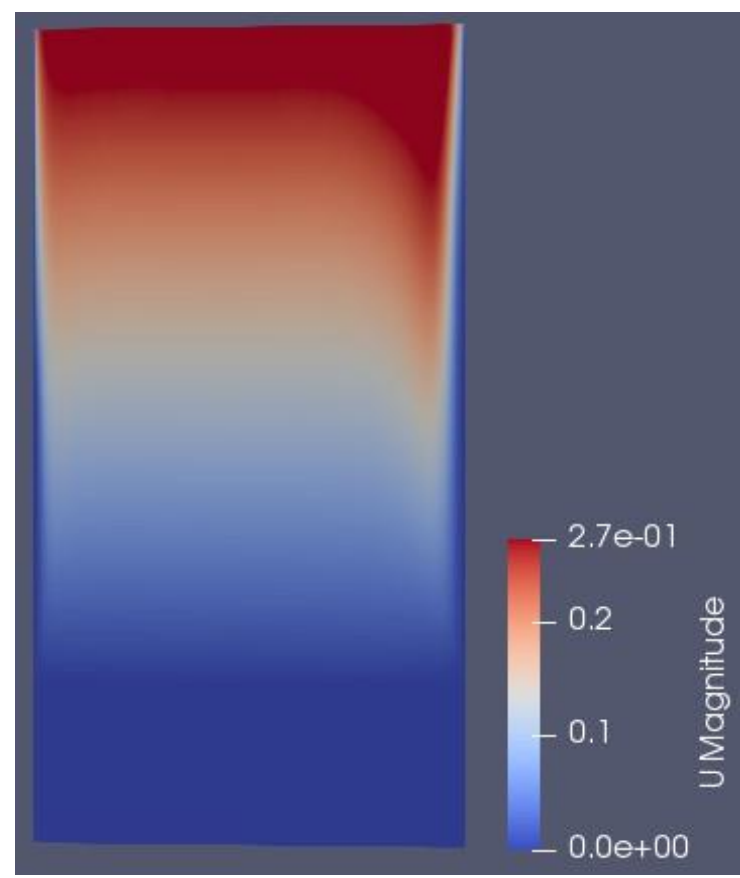

(c) $\mathrm{t}=30$ seconds

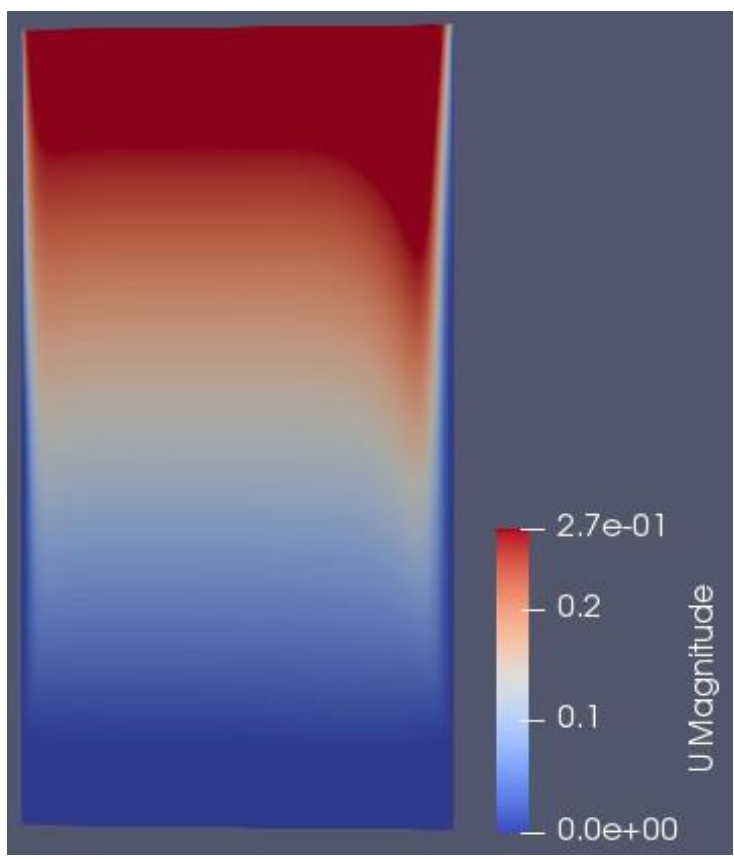

(b) $\mathrm{t}=15$ seconds

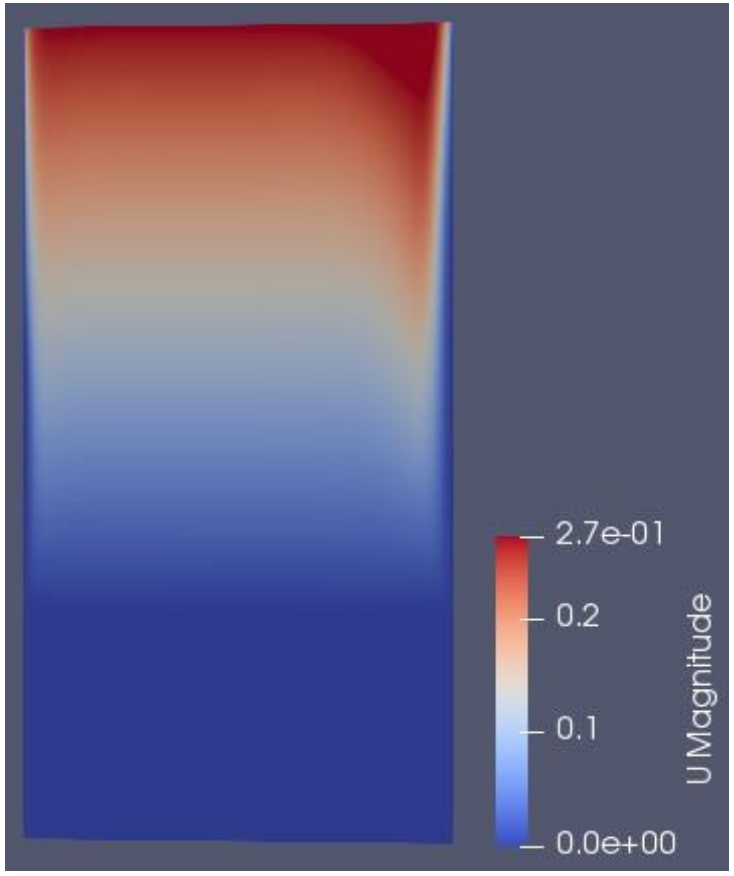

(d) $\mathrm{t}=45$ seconds

41 This work is licensed under a Creative Commons Attribution 4.0 International License. 
Figure 6: A graph of Vapour Velocity against time within a water storage tank

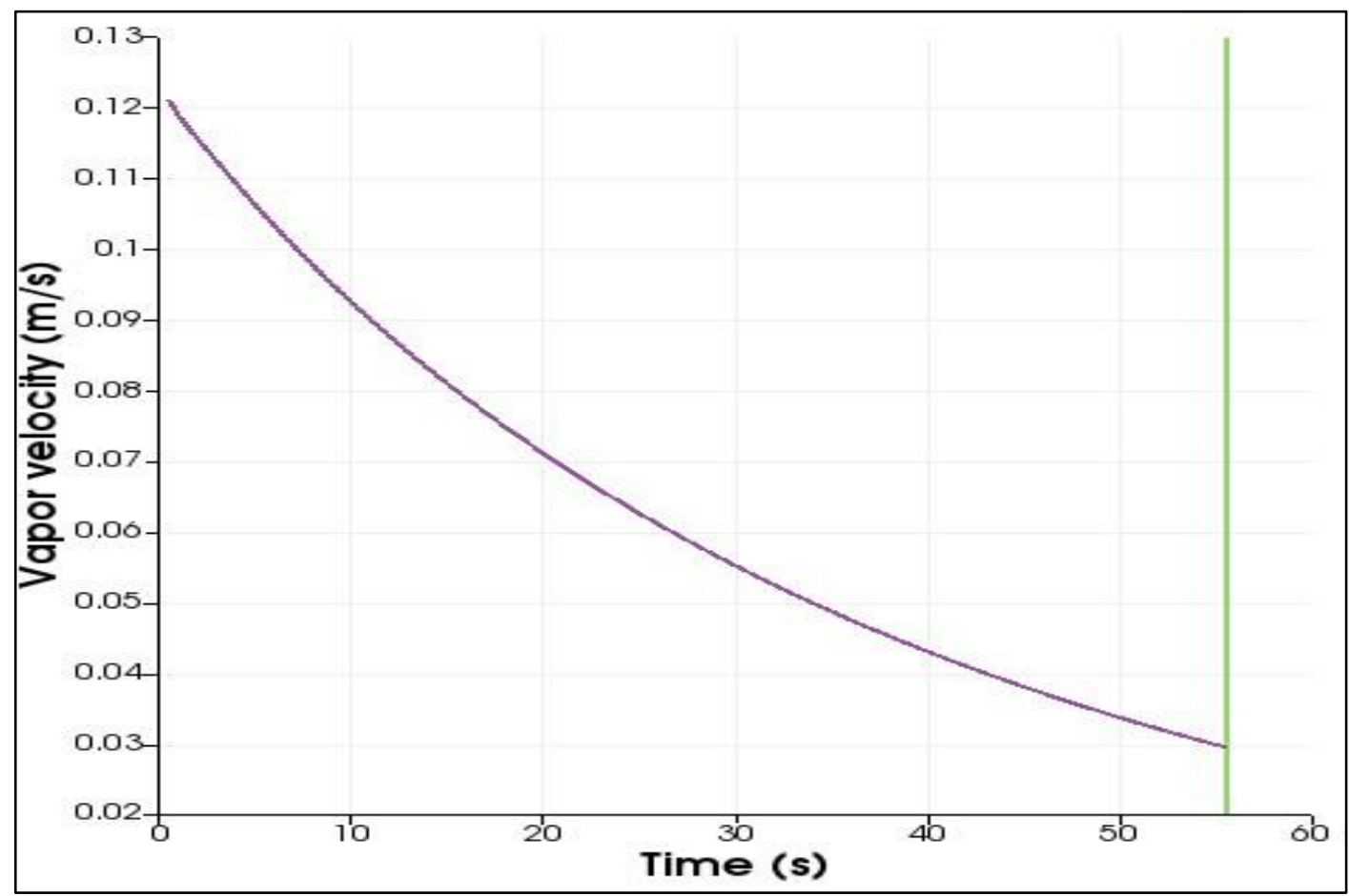

Figure 7: Vapour pressure distribution at $t=0,15,30$ and 45 seconds, within a water storage tank

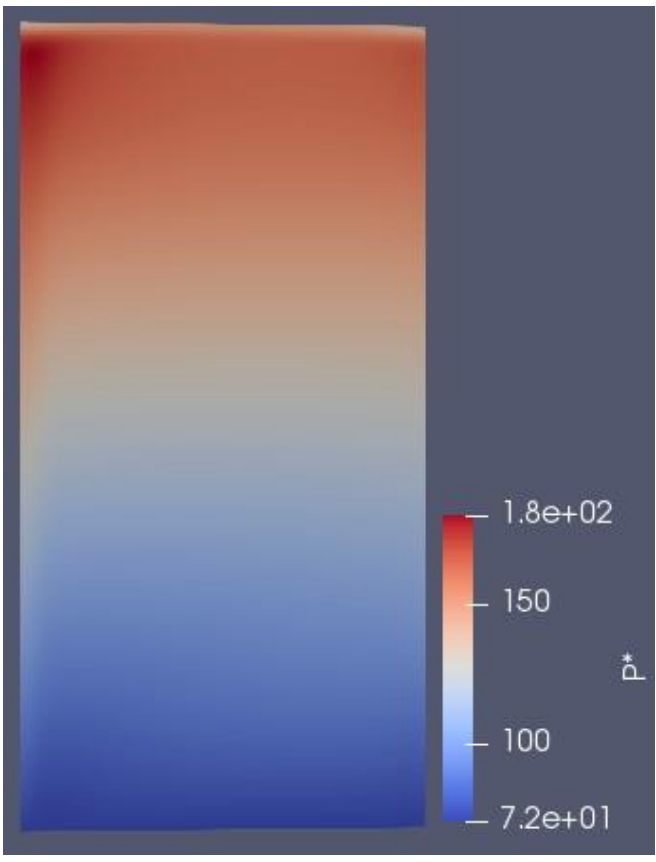

(a) $\mathrm{t}=0$ seconds

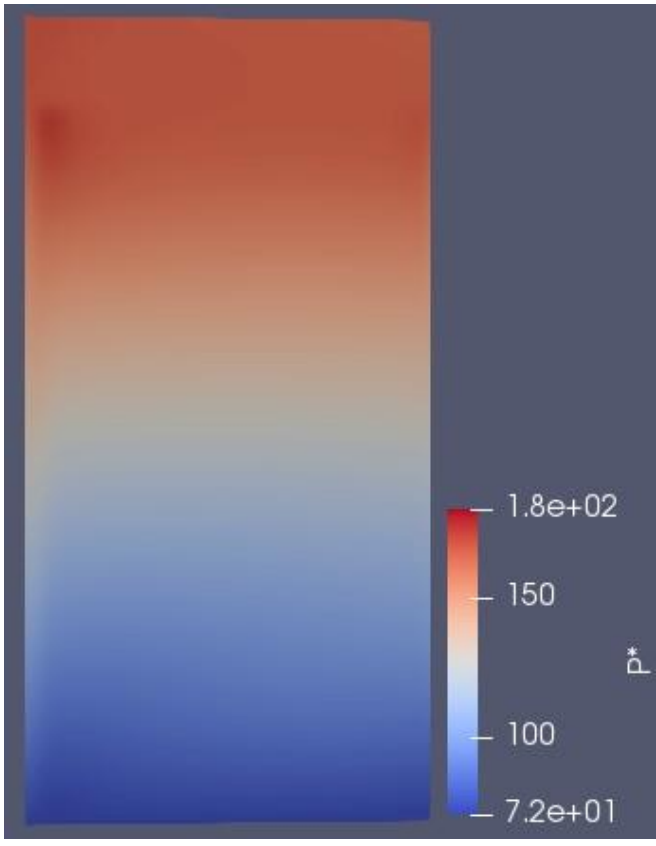

(b) $\mathrm{t}=15$ seconds

42 | This work is licensed under a Creative Commons Attribution 4.0 International License. 

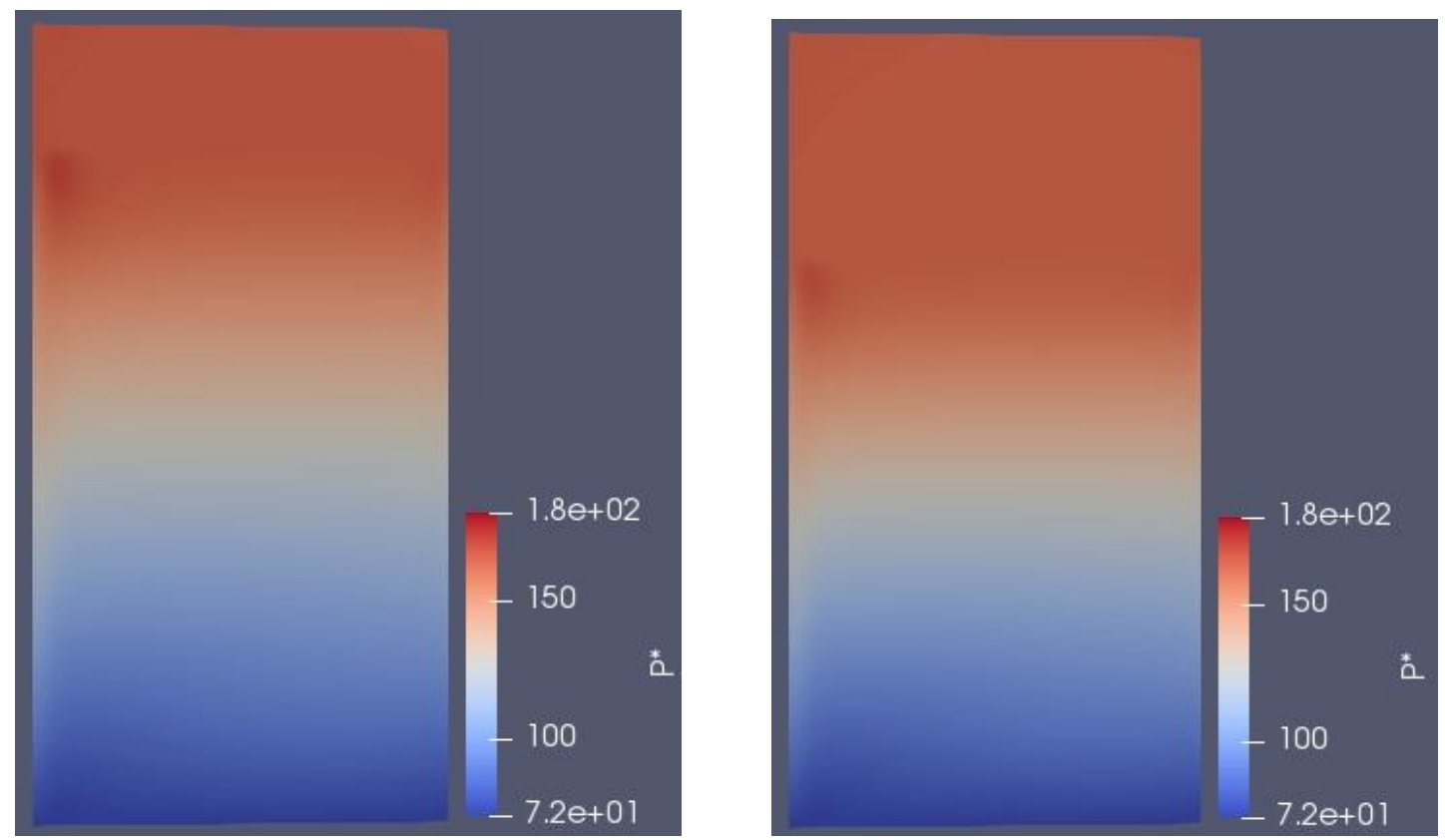

(c) $\mathrm{t}=30$ seconds

(d) $\mathrm{t}=45$ seconds

Figure 8: A graph of Vapour Pressure against time within a water storage tank.

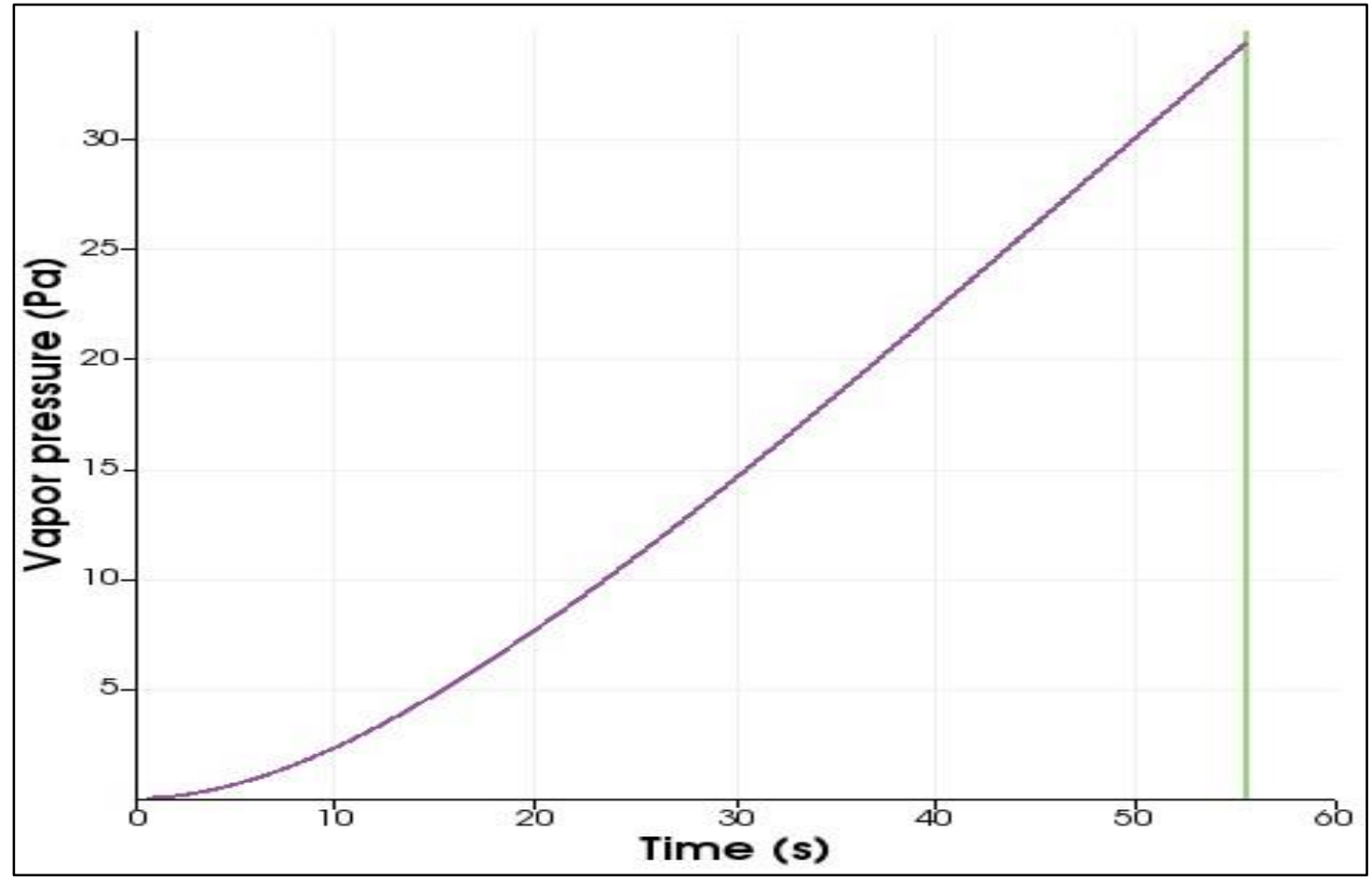

43 | This work is licensed under a Creative Commons Attribution 4.0 International License. 
Figure 9: A graph of Evaporation rate against time within a water storage tank

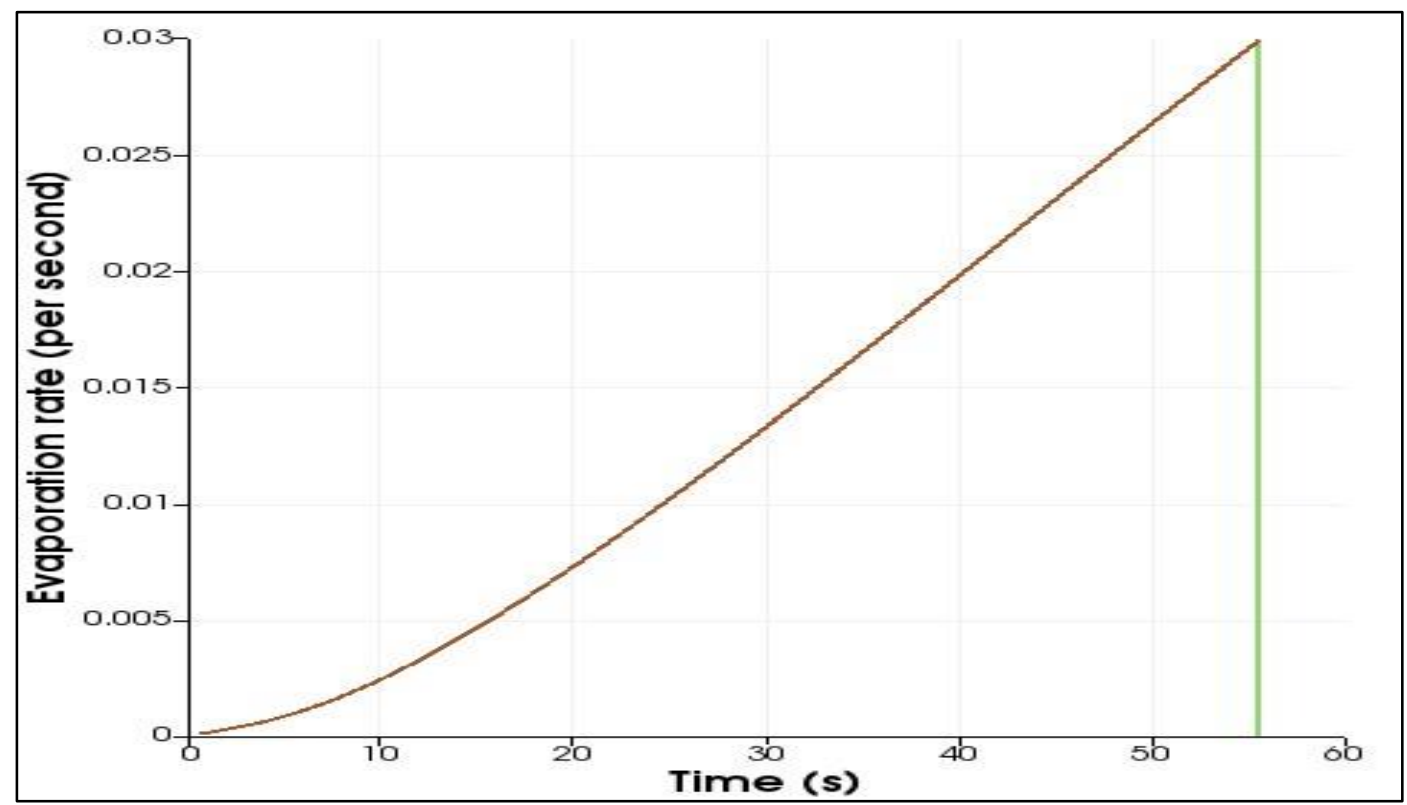

Figure 9 shows that the evaporation rate increases gradually with time. This gradual increase in the rate of evaporation is influenced by the water temperature, vapour pressure and vapour velocity fields.

\section{DISCUSSION OF RESULTS}

\section{Experimental Determination of Residual Chlorine}

From Table 1, experimental results show that the concentration of residual chlorine decreases with increasing temperature, as may be seen graphically in Figure 2. Residual chlorine concentration levels were found to be higher at a lower temperature. These results suggest that a higher temperature allows for a more rapid breakdown of the residual chlorine. The rates of chlorine reactions decrease with a decrease in temperature. Chlorine residual in water exits primarily as hypochlorous acid and hypochlorite ion. Higher water temperature leads to greater dissociation of hypochlorous acid, releasing chlorine as gas/vapour, hence reducing the residual chlorine concentration in the water within the storage tank.
Effects of Water Temperature, Vapour Pressure and Vapour Velocity on Evaporation

Figure 3 shows water temperature distributions at $\mathrm{t}$ $=0,15,30$ and 45 seconds within a storage tank. Water temperature is seen to increase gradually from the top of the water surface in the storage tank. This is because of the temperature boundary condition applied at the top of the storage tank. From Figure 4, there is initially a sharp increase in the temperature with time for about 3 seconds. This shows a linearly direct relationship between temperature and time. Thereafter, a parabolically increasing curve is produced, which later produces a turning point as a maximum. This generally means that there is an increase in the water temperature and later a fall in the temperature. High water temperatures enable the water molecules to move rapidly, hence escaping faster into the vapour phase. Therefore, increasing water temperature increases vaporization as more of the water molecules acquire kinetic energy to turn into vapour. The fall in the water temperature results from the escaping water molecules which take away energy from the water surface. In the water storage tank, conservation of 
kinetic energy enables the water to cool as well as the vapour in contact with it.

Figure 7 shows that vapour pressure within the water storage tank increases with time with a graphical illustration shown in Figure 8. When the water temperature rises, its molecules acquire sufficient kinetic energy to overcome the forces holding them in the water and they escape into the vapour phase. By escaping into vapour, a large number of molecules is accumulated into the vapour phase above the water, and this produces a pressure called vapour pressure. Increasing the water temperature increases both the average kinetic energy of the molecules in the water and the range of kinetic energy of the individual molecules. A fraction of the water molecules acquires energy enough for them to overcome the forces holding them but cannot escape into the vapour phase unless these molecules are at the water surface. The initial vapour pressure within the storage tank is approximately zero since there are yet no molecules in the vapour phase. Some molecules at the water surface, however, acquire enough kinetic energy to escape from the liquid to the vapour phase, hence increasing the vapour pressure within the tank. As soon as some vapour is formed, some of the vapour molecules collide with the water surface and reenter the liquid phase. As the number of vapour molecules increase, the number of collisions between vapour molecules and the surface too increase. In case the equilibrium is reached where the number of water molecules turning into vapour is equal to the number of vapour molecules turning into liquid phase, the vapour pressure remains constant.

Figure 5 shows vapour velocity distribution within a water storage tank at a time, $\mathrm{t}=0,15,30$ and 45 seconds. It is shown that the speed of vapour molecules decrease with an increase in time. This is further confirmed by Figure 6, where an exponentially decreasing curve with a maximum speed of $0.12 \mathrm{~ms}^{-1}$ is observed. In a closed water storage tank, an initial increase in the water temperature increases the kinetic energy of the molecules which increases the velocity of the vapour molecules. These vapour molecules collide with each other as well as also with the tank walls, and this slows down the speed of these vapour molecules hence the reduction in the vapour velocity. Also, as the vapour molecules accumulate in the space above the water surface, the mean distance of separation between the vapour molecules are reduced; hence the speed of such vapour molecules are minimized. However, as there is a decrease in the vapour velocity, evaporation is observed to increase, implying that there exists a more significant factor that favours evaporation to continue increasing.

\section{Effect of Evaporation on Residual Chlorine in a Water Storage Tank}

Figure 9 shows that the evaporation rate increases gradually for the first approximately 30 seconds, and thereafter, a sharp increase follows. Generally, there is an increase in the evaporation rate with time.

Chlorine being a volatile gas, can evaporate. Since the boiling point of chlorine is $-34.04{ }^{0} \mathrm{C}$ as compared with that of water which is $100{ }^{\circ} \mathrm{C}$, it means that chlorine evaporates faster than water. Therefore, at any particular temperature, residual chlorine in water within the storage tank always evaporates faster leaving the water with less or no residual chlorine to prevent the re-growth of microorganisms. This renders water unsafe for domestic consumption especially, drinking.

It can be inferred that there is an inverse relationship between temperature and residual chlorine in water since an increase in water temperature leads to a decrease in the amount of residual chlorine present in water. Now, since an increase in temperature is noted to increase the rate of evaporation, it also implies that the increasing rate of evaporation results in the loss of chlorine residual. Hence, residual chlorine in water within the storage tanks is 
highly affected by evaporation and this is against the null hypothesis.

\section{CONCLUSIONS}

\section{Experimental Determination of Residual Chlorine}

It is shown that an increase in water temperature results in an increase in the rate of decay of residual chlorine. This means that residual chlorine is lost as the water temperature gradually increases. Though the temperature is a vital component for water disinfection while using chlorine, moderate temperatures are preferred to increase the effectiveness of chlorine reactions. Otherwise, very high temperatures may negatively affect the expected outcome of the chlorination process. Previous research work shows that a decrease in the water temperature calls for more contact time between chlorine and water to ensure effective and efficient disinfection. In fact, at high temperatures, chlorine ends up evaporating from the water and this provides favourable conditions for re-growth of the micro-organisms and this results into waterborne disease outbreaks like amoebiasis, bacillary dysentery, cholera, among others, hence leaving water unsafe for consumption.

\section{Effects of Water Temperature, Vapour Pressure and Vapour Velocity on Evaporation}

From the results of the numerical simulations, it is confirmed that temperature has an effect on the evaporation rate of chlorinated water in a storage tank. It is deduced that an increase in temperature causes an increase in the evaporation rate. Water molecules at the surface acquire more (energy) heat from the top wall. Due to this increased heat, the water molecules gain kinetic energy resulting in more rapid movement of the water molecules which assists them to overcome the force of attraction and evaporate. Temperature and rate of evaporation are directly proportional to each other, meaning that an increase in water temperature leads to higher evaporation while a decrease in the water temperature results in lower evaporation rates.

The pressure exerted by a vapour in thermodynamic equilibrium with its condensed phase at a particular temperature in a closed water storage tank is an indication of evaporation rate within the tank. Vapour pressure leads to water molecules escaping from the liquid phase into the vapour phase. It also is observed that high vapour pressure indicates a high evaporation rate as expected. As the water temperature increases, the kinetic energy gained by the water molecules at the surface also increases. This increases the amount of water molecules changing into vapour, thereby increasing the vapour pressure. Our results also indicate a non-linear increase of vapour pressure with the rate of evaporation which agrees with the ClausiusClapeyron relation.

The speed at which vapour moves over the water surface affects the rate at which evaporation takes place. As the vapour moves further away from the water surface, the vapour pressure is reduced, which allows more water molecules to be converted into vapour. For a closed water storage tank, the vapour velocity is observed to gradually decrease with time. However, the evaporation rate is seen to increase despite the decrease in the vapour velocity. This indicates an inverse relationship between vapour velocity and evaporation rate for closed tanks, contrary to open water sources where an increase in vapour velocity causes an increase in the rate of evaporation.

\section{Effect of Evaporation on Residual Chlorine in a Water Storage Tank}

Residual chlorine is easily lost from water through evaporation. Chlorine is a volatile solute while in water and this means that chlorine molecules are able to diffuse in water and escape into vapour over time. Increasing the water temperature speeds up the evaporation rate. Chlorine has a very low boiling point (at $-34.04{ }^{\circ} \mathrm{C}$ ) and this means that the residual 
chlorine in water evaporates faster than water which has a boiling point of $100{ }^{\circ} \mathrm{C}$. Therefore, once there is evaporation taking place within the water storage tank, residual chlorine evaporates and in case of a high increase in the evaporation rate, it could result in little or no residual chlorine left in the water within the storage tank.

Residual chlorine is easily lost from water through evaporation. Chlorine is a volatile solute while in water and this means that chlorine molecules have the ability to diffuse in water and escape into the vapour phase over time. Increasing the water temperature speeds up the evaporation process. Also, when chlorine is added to water in the gaseous form, hypochlorous acid ( $\mathrm{HOCl})$, which is the effective antimicrobial agent is produced. Chlorine itself doesn't make much micro-organism killing, but it is responsible for odour as it does not completely react with water, and some of it remains in the form of dissolved gas. When chlorinated water is allowed to stay in the storage tank for so long, some of the chlorine will in turn evaporate, whereupon both the chlorine odour and amount of $\mathrm{HOCl}$ in water will diminish. This is because as some of the chlorine departs, the $\mathrm{HOCl}$ in the water produces more of it. The longer the water is kept in the storage tank, the less $\mathrm{HOCl}$ antimicrobial power it will have and the more susceptible it will be to recontamination with micro-organisms.

\section{Data Availability}

The data used to support the findings of this study are available from the corresponding author upon request.

\section{Conflicts of Interest}

The authors declare that there are no conflicts of interest regarding the publication of this paper.

\section{Nomenclatures}

\section{SymbolQuantity Units}

\begin{tabular}{|c|c|c|}
\hline$V$ & luid velocity vector & \\
\hline$C$ & Accommodation coefficient & \\
\hline$m$ & Mass of a molecule & \\
\hline$m$ & Rate of mass transfer $\quad\left[\mathrm{kgm}^{3} \mathrm{~s}^{-1}\right]$ & \\
\hline$M$ & Molar mass & \\
\hline$p$ & Thermodynamic pressure & \\
\hline p_rgh & Pressure excluding hydrodynamic pressure & {$\left[\mathrm{Nm}^{-2}\right]$} \\
\hline$q$ & Heat flux & \\
\hline s & Surface & \\
\hline $\mathrm{t}$ & Temperature $\quad[K]$ & \\
\hline$v$ & Specific volume $\left[\mathrm{m}^{3} \mathrm{~kg}^{-1}\right]$ & \\
\hline$V$ & Volume & \\
\hline
\end{tabular}

47 | This work is licensed under a Creative Commons Attribution 4.0 International License. 
East African Journal of Engineering, Volume 3, Issue 1, 2021

Article DOI: https://doi.org/10.37284/eaje.3.1.357

$\alpha \quad$ Phase fraction

$\rho \quad$ Density $\quad\left[\mathrm{kgm}^{-3}\right]$

$\kappa \quad$ Curvature

$k \quad$ Thermal conductivity $\quad\left[W^{-1} K^{-1}\right]$

$\mu ; \quad$ Fluid viscosity $\quad\left[m^{2} s^{-1}\right]$

$m_{e} \quad$ Rate of evaporation $\quad\left[s^{-1}\right]$

$\eta$; $\quad$ First-order decay constant $\quad\left[s^{-1}\right]$

$\eta_{b ;} \quad$ bulk decay rate constant $\quad\left[s^{-1}\right]$

$\eta_{w ;} \quad$ wall decay rate constant $\quad\left[s^{-1}\right]$

$c_{p ;} \quad$ Specific heat capacity $\quad\left[\mathrm{Jmol}^{-1} \mathrm{~K}^{-1}\right]$

\section{REFERENCES}

AWWARF, D. (1996). W2 tzw. Internal corrosion of water distribution Systems, 1, 900-996.

Batchelor, G. K. (1967). An introduction to fluid dynamics. 1967. Cambridge: UP xviii 615.

Brackbill, J. U., Kothe, D. B. \& Zemach, C. (1992). A continuum method for modeling surface tension. Journal of Computational Physics, 100(2), 335-354.

Chambers, A. (1995). Booktalk. Thimble Press.

Clasen, T. \& Edmondson, P. (2006). Sodium dichloroisocyanurate (nadcc) tablets as an alternative to sodium hypochlorite for the routine treatment of drinking water at the household level. International journal of hygiene and environmental health, 209(2), 173181.

Hua, F., West, J., Barker, R. \& Forster, C. (1999). Modelling of chlorine decay in municipal water supplies. Water Research, 33(12), 2735-2746.

Jasak, H. (1996). Error analysis and estimation for the finite volume method with applications to fluid flows. Doctorate Thesis. Department of Mechanical Engineering Imperial College of Science, Technology and Medicine

Koutsoyiannis, D. (2012). Clausius-clapeyron equation and saturation vapour pressure: simple theory reconciled with practice. European Journal of Physics, 33(2), 295-300.

Noh, Y., Kim, S.-H., Choi, S.-U. \& Park, J. (2016). A review study on major factors influencing chlorine disappearances in water storage tanks. Journal of Korean Society of Disaster and Security, 9(2), 63-75.

Persad, A. H. \& Ward, C. A. (2016). Expressions for the evaporation and condensation coefficients in the hertz-knudsen relation. Chemical Reviews, 116(14), 7727-7767.

Pickford, J. (1996). Reaching the unreached: challenges for the 21st century. Proceedings of the 22nd WEDC Conference, New Delhi, India, 9-13 September 1996. Water, Engineering and Development Centre, Loughborough University.

Powell, J. C., Hallam, N. B., West, J. R., Forster, C. F. \& Simms, J. (2000). Factors which control

48 This work is licensed under a Creative Commons Attribution 4.0 International License. 
bulk chlorine decay rates. Water Research, 34(1), 117-126.

Rossman, L. A., Clark, R. M. \& Grayman, W. M. (1994). Modeling chlorine residuals in drinkingwater distribution systems. Journal of Environmental Engineering, 120(4), 803- 820.

Sun, D., Xu, J. \& Chen, Q. (2014). Modeling of the evaporation and condensation phase change problems with fluent. Numerical Heat Transfer, Part B: Fundamentals, 66(4), 326-342.

Vyzikas, T., Nilsson, H. \& Andric, J. (2015). Cfd with opensource software. pp. 5-32.

49 This work is licensed under a Creative Commons Attribution 4.0 International License. 